\title{
IDENTIFICAÇÃO CRIMINAL EM ADOLESCENTES
}

\section{ARTIGO ORIGINAL}

SALLES, Claudia Regina de Oliveira ${ }^{1}$

BARROS FILHO, Jorge ${ }^{2}$

SALLES, Claudia Regina de Oliveira. BARROS FILHO, Jorge. Identificação Criminal em Adolescentes. Revista Científica Multidisciplinar Núcleo do Conhecimento. Ano 05, Ed. 10, Vol. 21, pp. 96-110. Outubro de 2020. ISSN: 2448-0959, Link de acesso:https://www.nucleodoconhecimento.com.br/lei/criminal-em-adolescentes

\section{RESUMO}

O presente trabalho irá retratar a identificação criminal em casos que envolvem menores de idade, a qual é uma importante ação para a confirmação da identidade de um indivíduo acusado de um ato ilícito, avaliando qual deve ser a medida tomada para que haja a resolução deste fato sem ferir os direitos e as garantias individuais, considerando que estes indivíduos menores recebem punições mais brandas em relação a um adulto, pois são amparados legalmente de maneira diferenciada em relação a um adulto comum, assim a conduta de um adulto é vista como crime, mas quando cometida por um menor é tida como ato infracional. Neste sentido o Estatuto da Criança e do Adolescente visa preservar estes menores de idade de qualquer exposição desnecessária, por isso prevê que não ocorra a identificação criminal se os menores apresentarem sua identificação civil, as exceções ocorrem em caso de dúvida sobre a veracidade ou falta deste tipo de documento. Diante desta temática,

${ }^{1}$ Graduada (Licenciada) em Administração Letras pela UFG - Universidade Federal do Goiás, e Acadêmica do 10 Período do Curso de Direito na UNIRG - Universidade de Gurupi.

2 Orientador. Graduação em Direito; Especialização em Direito Processual Civil, Especialização em Tribunal do Júri Processual. 
objetiva-se demonstrar com esse estudo quais as possibilidades em que a identificação criminal do adolescente pode ser realizada, através de uma pesquisa qualitativa com base bibliográfica, utilizando de artigos, livros, legislações e outros materiais que retratam essa temática e desta maneira alcançar finalmente a compreensão dos procedimentos adotados quando se envolve um menor infrator. Portanto, foi possível notar a demanda por uma ampliação das hipóteses de identificação criminal de menores, em que a legislação passe a tratar estes casos com maior especificidade, determinando todas as possibilidades e os procedimentos.

Palavras-chave: Identificação criminal, menores, ato infracional, veracidade, identificação civil.

\section{INTRODUÇÃO}

A identificação criminal do réu é o procedimento básico da perseguição criminal. $O$ Código de Processo Penal brasileiro enumera esse procedimento como uma das medidas que as autoridades policiais devem tomar imediatamente ao detectar um crime ou infração penal (artigos 6 inciso VIII).

Este procedimento pode trazer ações probatórias mais simples e importantes às autoridades competentes para apuração de casos envolvendo menores. É importante estudar esses casos para identificar crimes cometidos por crianças e jovens para que possam tomar as medidas cabíveis de acordo com o Estatuto da Criança e do Adolescente (BOCATO, 2013).

É preciso levar em conta que os jovens menores de 18 anos ainda estão em formação e não são plenamente capazes de compreender o que é certo e o que é errado. Essa idade está incluída no padrão biológico, desta forma, o artigo 228 da Constituição Federal estabelece que os menores de dezoito anos são criminalmente responsáveis, observadas as regras de legislação especial.

Diante do exposto o presente projeto, com base na atual legislação, visa responder a seguinte problemática: $A$ ação de identificação criminal em adolescentes menores de 
idade da forma como vem sendo realizada é legal? Investigar a legalidade da identificação criminal em adolescentes menores de idade e identificar qual o procedimento mais utilizado conforme nosso ordenamento jurídico.

É indispensável que os operadores do Direito, os servidores públicos especialmente os que trabalham com segurança pública compreendam o processo de identificação criminal frente a um indivíduo menor de idade, o qual é respaldado por diversas leis que dão a ele amparo diferenciado, entendendo-se este processo de identificação criminal pode ou não ocorrer com este. Assim, trabalhar esta temática é essencial tanto para os Operadores do Direito quanto para a sociedade em geral, para que assim possam determinar qual conduta seria mais propícia ao caso, protegendo os direitos individuais do menor.

\section{A IDENTIFICAÇÃO CRIMINAL}

A vida em sociedade faz com que os indivíduos possuam uma necessidade de diferenciar-se dos demais, principalmente daqueles que realizam delitos. Assim, os indivíduos ao longo do tempo procuraram metodologias para identificar aqueles considerados como antissociais dos considerados bons cidadãos, inclusive como modo de resguardar-se. Diversos tipos de processos surgiram junto a necessidade ou à medida que um tornava-se insuficiente ou defasado os métodos já existentes para a individualização e identificação das pessoas.

Para Robles (2004), o reconhecimento é um processo ou conjunto de processos que visam estabelecer a identidade de uma pessoa. Por outro lado, Tourinho Filho (1999) o definiu como um conjunto de dados e sinais que caracterizam uma pessoa. Por ser a ciência forense o estudo das autoridades responsáveis pela elucidação de crimes, ela pode identificar criminosos em diversas situações (VELHO; GEISER; ESPÍNDULA, 2017).

De acordo com Araújo (2006) o primeiro modo de identificação utilizado tanto pelo meio civil quanto criminal foi o nominal. Com a elaboração de uma ficha com o nome do indiciado e algumas de suas características, ainda hoje utiliza-se esta metodologia, 
e mais detalhadamente quando ocorre o indiciamento do indivíduo nas delegacias, por meio do preenchimento do Cadastro de Antecedentes (MIRABETE, 2000). Por isso, muitos criminosos fazem usos de apelidos ou nomes falsos para evitar a descoberta de seus verdadeiros nomes e principalmente a sua publicidade, e por causa deste fato o método de identificação nominal não pode ser usado isoladamente, é muito importante que esteja associado ao dactiloscópico devido ao perigo de se estar diante de um falsário cujo nome não é verdadeiro. Além disso, há também perigo em relação aos homônimos porque diferentes pessoas possuem nomes idênticos, ocasionando possíveis confusões na esfera civil.

O nome é uma forma de personalização na sociedade mesmo após a morte, que consta como um dos direitos da personalidade no Direito Civil. O primeiro registro histórico do uso de nomes compostos data de 2850 a.C., quando um imperador chinês ordenou o uso de nomes ou sobrenomes para personalizar melhor as pessoas (VENOSA, 2003).

Atualmente, como muitos criminosos usam apelidos para evitar descobrir seus nomes reais, esse método não deve ser usados isoladamente, principalmente devido ao perigo de se passar por seus falsificadores. O nome exibido não é o nome real e é ideal para associá-lo a métodos de impressão digital.

Num segundo momento, o processo utilizado era o de Ferrete, um modo de identificação humana considerado extremamente cruel, este utilizava um ferro em brasa para marcar o corpo do criminoso ou do escravo fugitivo com a letra indicativa ao crime e ao país (ARAÚJO, 2006).

O uso do ferrete tem dois propósitos, punição e identificação. É um costume antigo, usado até mesmo durante o julgamento imperial, incluindo o uso de alicates, pinças, flagelos e outras ferramentas para remover partes do corpo, como seios, dedos, pênis, unhas e identificar pessoas por partes ausentes, e por ser considerada desumana, essa prática também foi abandonada. 
Contudo, este consegue ser menos cruel que o da mutilação, utilizado na Idade Média, com emprego de instrumentos próprios para arrancar pedaços de tecido do corpo (SOBRINHO, 2003). Este método ainda é utilizado no Oriente Médio com o objetivo de marcar e punir o infrator conforme o crime, contudo há vários casos em que a mutilação é feita independentemente do tipo de crime (ARAÚJO, 2006).

O quarto processo utilizado ao longo da história foi com a utilização de tatuagens, influenciado por um costume indígena, também conhecido como Sistema Cromodérmico, foi sugerido por Jeremy Benthan a partir de 1832, o qual propôs inicialmente que a tatuagem fosse feita no antebraço direito com letras que pudessem identificar civilmente o indivíduo e números para a identificação criminal (ARAÚJO, 2006). Para a época o modo de identificação era disposto como um avanço, mas aos poucos tornou-se ineficaz devido as transformações naturais que o ser humano sofre, o Brasil implantou este processo em 1891.

O antropométrico foi um dos processos que se seguiu na história, com base na Antropologia investigações eram realizadas sob detalhes antropométricos de um criminoso, de acordo com as teorias do psiquiatra Cesare Lombroso, o qual determinava que o crime era decorrente da natureza criminosa que o autor possuía, ou seja, já nascia com traços que eram diferentes dos indivíduos honestos. Estes tinham traços como o tamanho do crânio, da fosseta occipital, e outros, fatores que faziam estes serem inferiores, e, então, inadequados para conviver em sociedade (SHECAIRA, 2008).

Esta metodologia de Cesare Lombroso gerou múltiplas críticas porque não podia ser utilizado com menores de 21 anos e maiores de 65 tendo em vista as mudanças corporais que ocorrem nestas idades, e ainda tinha os casos de gêmeos idênticos. Além disso, certas partes do corpo não possuem medidas precisas, e geravam constrangimento, situações vexatórias (SOBRINHO, 2003).

Sobrinho (2003) explicita que a fotografia sinalética, frente e perfil, é ainda utilizada em cadastros criminais e foi arquitetado por Alphonse Bertillon, o mesmo autor do 
método antropométrico que foi disposto anteriormente, notável que este autor assimilava a imagem do indivíduo a criminalidade.

Segundo Araújo (2006) o processo Odontológico de Amoedo surgiu em 1897 como ferramenta científica provinda do cubado Oscar Amoedo Valdés, contudo, alguns fatores geravam sua ineficácia na época, como a falta de tratamentos dentários, os dentes eram arrancados, dificultando a identificação e os estudos posteriores, neste sentido, o método ainda é utilizado para identificar cadáveres carbonizados, mumificados e em ossadas.

O nono processo é o Papiloscópico que se fundamenta na dermatoglifia, o estudo da configuração das linhas e estrias das mãos e dos pés. Em seguida há o processo de identificação por meio do DNA, o exame é complexo, demorado, e utiliza reagentes caros, ainda precisa ser realizado por um profissional competente, e é utilizado em maioria nos casos onde outros métodos não podem ser suficientes (SOBRINHO, 2003).

A identificação pelo íris foi outro processo descoberto, mas passou a ser mais presente para a identificação funcional, em grandes empresas, ou mesmo para a utilização de senhas ou cartões magnéticos. Contudo, este por ser de difícil armazenamento e confronto, torna-se ineficaz no dia-a-dia (SOBRINHO, 2003).

Quando um indivíduo comum é civilmente identificado ele é quem realiza tal requerimento nos órgãos de Identificação e assim é gerado para ele um cadastro com um número de Registro Geral ( $R G$ ) que vem anotado em um documento popularmente conhecido como RG ou Carteira de Identidade.

Há base científica suficiente para usar a datiloscopia como o principal meio de identificação criminal, porque pode ser verificada desde os seis meses de existência do feto até a morte do indivíduo. Assim, conta-se com a imutabilidade, o que significa que uma vez formado, o design digital não será mais alterado; diversidade, dois dedos não podem coincidir em seu desenho, e; classificabilidade, é possível classificar os desenhos em tipos e subtipos básicos (RABELO, 1996). 
Atualmente quando um processo de identificação ocorre por meio de um inquérito policial, e se no ato da identificação do indivíduo ele não apresentar um documento de identificação válido, é gerado um RG criminal para este sentenciado.

Assim, nos órgãos de identificação é gerado um cadastro com um número criminal para o indivíduo indiciado, ligado a ficha do seu RG civil, tornando o acesso a sua ficha criminal mais fácil de ser acessada pelo judiciário. Frisa-se que somente os órgãos de identificação possuem este acesso.

\section{PRINCÍPIOS LEGAIS DA IDENTIFICAÇÃO CRIMINAL}

A Identificação Criminal foi regulamentada por meio do art. 5o da Lei 12.037/12 e pode ocorrer por meio do processo datiloscópico, fotográfico e coleta do material biológico para a obtenção do perfil genético, este último foi incluído através da Lei 12.654/12.

De acordo com Sobrinho (2003) a identificação criminal coopera com o Direito Processual Penal possibilitando o conhecimento ou a confirmação da identidade do agente que praticou o crime em apuração, e torna mais fácil fazer com que este cumpra com as sanções decorrentes do crime praticado. Além disso, em que servirá como prova colocada à disposição dos indivíduos inocentes que possam demonstrar não serem as verdadeiras autoras do ato ilícito, quando houver um equívoco de identidade.

Há a determinação de que aquele que for civilmente identificado por qualquer documento não será submetido à identificação criminal, contudo, o artigo $3^{\circ}$ da mencionada Lei estabelece algumas exceções, quando:

I - o documento apresentar rasura ou tiver indício de falsificação;

II - o documento apresentado for insuficiente para identificar cabalmente o indiciado;

III - o indiciado portar documentos de identidade distintos, com informações conflitantes entre si; 
IV - a identificação criminal for essencial às investigações policiais, segundo despacho da autoridade judiciária competente, que decidirá de ofício ou mediante representação da autoridade policial, do Ministério Público ou da defesa;

$\mathrm{V}$ - constar de registros policiais o uso de outros nomes ou diferentes qualificações;

$\mathrm{VI}$ - o estado de conservação ou a distância temporal ou da localidade da expedição do documento apresentado impossibilite a completa identificação dos caracteres essenciais. (BRASIL, 2009)

Segundo Lopes (2007) este procedimento coloca em perigo a eficácia ao direito de não produzir provas contra si mesmo, quando o acusado se recusa a fornecer suas digitais, por exemplo, o juiz irá determinar a extração compulsória de ofício. A identificação criminal precisa ser realizada de modo a evitar ao máximo os constrangimentos e deve ser juntada aos autos da comunicação da prisão em flagrante, ou do inquérito policial, ou outra maneira de investigação, mas não pode ser mencionada em atestados de antecedentes ou informação não destinadas ao juízo criminal, antes do trânsito em julgado da sentença condenatória.

A identificação por meio fotográfico, se rejeitada, em caso de absolvição ou não oferecimento da denúncia faculta-se ao sujeito requerer a retiradas dos autos do processo ou inquérito, desde que apresente provas de sua identificação civil.

No tocante aos dados relacionados ao perfil genético, estes são armazenados em um banco de dados sigiloso, o Banco Nacional de Perfis Genéticos, o qual foi regulamentado pelo Decreto 7.950/2013, que visou criar uma Rede Integrada de Bancos de Perfis Genéticos, capaz de permitir o compartilhamento e a comparação de perfis genéticos constantes dos bancos da União, Estados e do Distrito Federal.

Lopes (2007) explicita que não é favorável banalizar a intervenção corporal, já que representa uma ampla violação da privacidade, integridade física, e dignidade da pessoa humana, além de ferir mortalmente o direito de silêncio negativo. Várias problemáticas provêm desta questão, onde muitos casos recorrem a afirmativa de "essencial para as investigações" sem ao menos determinar em que tipos de crimes isto seria possível. 
Durante as investigações tanto a essencialidade quanto a autorização judicial se fazem necessárias para que abusos não ocorram, além disso, um terceiro requisito é defendido por Nicolitt (2013), o consentimento informado do indiciado, e Queijo (2012) fortalece este argumento pontuando que não se pode negar o princípio de que ninguém é obrigado a produzir prova contra si mesmo, por isso a colaboração é essencial.

Desta forma, a recusa em cooperar não pode configurar em crime de desobediência, nem se pode admitir a execução coercitiva à produção de prova. A Lei de Identificação Criminal dispõe em seu artigo $5^{\circ}$ que 0 armazenamento ocorrerá em um banco de dados de perfis genéticos, gerenciado por unidade oficial de perícia criminal, estas amostras não podem revelar traços somáticos ou comportamentais das pessoas. Ainda, este perfil genético será excluído do banco de dados ao término do prazo estabelecido em lei para a prescrição do delito, ou em data anterior definida judicialmente.

É notável que não houve a regulamentação da exclusão do perfil diante de possível arquivamento do inquérito policial ou sentença absolutória, por isto este projeto precisa receber certas críticas, a coleta de material genético, nestas perspectivas, fere a dignidade humana. Ainda, garante amplas possibilidades quanto à coleta de material humano, e a exclusão deste só ocorre quando há a prescrição do caso, o que não é favorável, visto que o arquivamento ou absolvição deveriam autorizar esta exclusão.

Destarte, não há a definição dos crimes que seriam praticados com natureza grave contra a pessoa para autorizar a coleta deste material e inclusão nos bancos de dados. Do mesmo modo não esclarece se somente as condenações transitadas em julgado com estas características podem demandar esta ação, e, por último, não há a hipótese de exclusão de dados daqueles que foram condenados por tais delitos.

Entretanto, este projeto não prevê a recusa do investigado ao fornecimento do material genético, bem como as consequências de tal recusa. Diante disto, compreende-se que a identificação criminal possui diversas especificidades que não 
receberam legislação devida, causando dúvida ao sistema judiciário, como ocorre também nos casos que envolvem menores de idade.

\section{IDENTIFICAÇÃO CRIMINAL ENVOLVENDO MENOR DE IDADE}

A Convenção sobre os Direitos da Criança, ratificada pelo Brasil em 24 de setembro de 1990 e em vigência desde 23 de outubro de 1990, determina que a criança é todo ser humano com menos de dezoito anos de idade, a não ser nos casos previstos na lei em que está alcance a maioridade antes.

O crime é um fenômeno que assola a sociedade. Em certas circunstâncias, no Brasil, essa questão acarreta um preconceito perigoso, porque é sabido que a participação de menores está aumentando, os criminosos usam fatores relacionados a classe social para incentivar muito a participação de menores (MONTEIRO; SANTOS JúNIOR, 2007).

Saab (2017) explicou que o aumento de atividades criminosas graves de menores de classe média e alta exclui completamente a visão de que os menores são obrigados a atuar neste meio devido à falta de infraestrutura familiar. Portanto, os motivos da marginalização dos adolescentes são muito amplos e desconhecidos, não se limitando à falta de poder aquisitivo.

A Magna Carta estipula que os menores de dezoito anos estão sujeitos a responsabilidade penal, mas de leis especiais. Por sua vez, a Lei Penal estipula que os menores de 18 anos não são inimputáveis em seu artigo 27, desta maneira, o Estatuto da Criança e do Adolescente segue essa regra e impõe ação disciplinar sobre sanções e outras medidas de proteção.

Todas as condutas tipificadas penalmente como crime ou contravenção, quando praticada por criança ou adolescente, é denominada "ato infracional". Esta é uma norma especial do Direito da Criança e do Adolescente, que com esta designação diferenciada amplia o caráter extrapenal da matéria, assim como o atendimento a ser prestado a este indivíduo (DIGIÁCOMO; DIGIÁCOMO, 2010). 
O objetivo do ECA é dar proteção integral às crianças e aos jovens, tendo em vista sua situação especial de pessoa em desenvolvimento e suas condições de integração, preocupa-se em dar tratamento diferenciado da legislação geral. Pela descrição do Estatuto, não há diferença entre os conceitos de crime e ato infracional, devendo-se considerar que ambos pertencem à categoria de atos ilícitos. A diferença entre estes termos deve-se apenas ao fato de que é necessário enfatizar o tratamento especial de pessoas menores de 18 anos.

Conforme Trindade (1996) as crianças e adolescentes, em certo sentido, aceitam com entusiasmo todas as experiências que vivenciaram. Isso é sempre novo em suas vidas. Eles não podem mediar entre o impulso e o mundo exterior, o que explica a não responsabilização geral exigida por lei, e carecem de experiência, requisito importante para agregar fatos às suas consequências. É por isso que eles devem ser impedidos de serem culpados.

Obviamente, as habilidades mentais dos jovens ainda estão se desenvolvendo, e o ambiente social em que vivem afeta sua personalidade atual e futura. Nesta fase, os indivíduos ainda não têm pleno conhecimento de suas ações, principalmente ações ilegais, que devem ser condenadas pela sociedade e pelo judiciário. A consciência de infringir a lei é muito pequena e depende do ambiente, da amizade e da relação dessas pessoas com o ambiente familiar em que vivem.

O Estatuto da Criança e do Adolescente determina que qualquer adolescente apreendido por força de ordem judicial ou apreendido em flagrante de ato infracional será encaminhado a autoridade competente. Assim, quando há uma repartição policial especializada para atender este adolescente e se tratando de um ato infracional realizado em conjunto com um maior, prevalecerá a atribuição da repartição especializada, que, após as providências necessárias e conforme o caso, encaminhará o adulto à repartição policial própria.

Nota-se que o processo de identificação criminal tratado pelo ECA respeita o fato de os adolescentes estarem submetidos a um regime jurídico diferenciado. 
A identificação compulsória do art. 109 da Lei n⒏069/1990, compreende a individualização datiloscópica e a fotográfica. As exceções apresentam-se em relação a desconfiança a respeito da veracidade do documento, ainda, considera-se que a submissão de um adolescente a vexame ou constrangimento é um crime previsto no artigo 232 do Estatuto (VERONESE, 2006).

Mas temos que nem sempre é possível individualizar dois ou mais adolescentes para aferir a autoria do ato infracional, apesar da identificação civil, a não ser por meio da identificação criminal, com base no princípio da dúvida fundada. Diante disto, Cury (2010) explicita a importância da realização desta identificação, considerando a indesmentível necessidade de conhecer os atributos físicos do eventual infrator em relação à sua identidade, em busca de comprovar sua participação, por isto, não se pode deixar de apurar devidamente um caso em decorrência de sua idade.

Segundo Elias (1994) o adolescente encontra-se amparado desde que possua qualquer documento que o identifique, como a certidão de nascimento ou a carteira de identidade fornecida pela Secretaria de Segurança Pública, e, desta maneira, só importa que este seja devidamente identificado. Nas exceções permitidas, quando se refere à confrontação, ocorrem em decorrência de casos onde menores já responsabilizados por atos infracionais utilizam de falsa documentação, como disposto pelo autor, o que ocorre com certa frequência.

São comuns casos onde adolescentes ao serem apreendidos atribuem-se a identidade de outro indivíduo, especialmente para que não seja devidamente contatada a prática de atos infracionais. Alguns chegam a apresentar certidões de nascimento de parentes próximos, ou mesmo se apresentarem como adolescentes, em busca de receberem a responsabilização diferenciada (ROSSATO; LÉPORE; CUNHA, 2011).

Elias (1994) afirma que ao mesmo tempo em que se quer evitar um ato que poderia ser vexatório ao menor, gerando até danos ao direito deste, não se pode deixar de tomar as medidas necessárias para identifica-lo corretamente se houver dúvida. Além disso, o autor pontua que um menor nunca receberá medidas de caráter punitivo, por 
isso, é preciso realizar uma análise em cada caso para examinar esta necessidade de identificação compulsória, e esta deve ocorrer sem danificar os direitos que lhes são devidos.

Tem-se então que um adulto será identificado criminalmente em determinadas situações, enquanto o adolescente será, no máximo, identificado compulsoriamente nas hipóteses apresentadas, e, ainda se nota que o ECA apresenta certa omissão quanto aos processos para a realização desta em casos de dúvida fundada e o que realmente deve ser feito com o material colhido na identificação (fotos, ficha...).

Portanto, nota-se a necessidade de ampliar as hipóteses de identificação criminal para - adolescente, bem como cadastro destas informações em bancos de dados apropriados aplicando-se as previsões de Lei ㄲo 8.069/1990 e Lei ㄲo12.037/2009, utilizando tais formas de modo em que a dúvida fundada recaia sobre uma das possibilidades do artigo $3^{\circ}$ da Lei de Identificação Criminal, levando em consideração o instituído no ECA.

\section{METODOLOGIA}

O presente trabalho segue uma linha qualitativa, em que lida com fenômenos realizando uma análise hermenêutica dos dados coletados. Este tipo de pesquisa torna possível a compreensão e interpretação do fenômeno, considera o significado que os outros dão às suas práticas (GONSALVES, 2003).

Deste modo, esta realiza uma fundamentada por meio de fontes bibliográficas como livros, artigos científicos, revistas, e textos extraídos da internet, consegue descrever ou explicar o tema, valendo-se de um aprofundamento na área desejada (VERGARA, 2006).

A base para os critérios de elegibilidade definiu informações de publicações científicas, revistas científicas e sites de universidades fornecidas pela base de dados como o Scielo. No entanto, decidiu-se procurar as informações mais recentes sem limite de tempo, assim, foram excluídas as publicações que não atingem o tema 
escolhido ou estão incompletas, e publicações duplicadas ou cujo conteúdo é muito semelhante a outro trabalho selecionado.

\section{CONSIDERAÇÕES FINAIS}

Diante das informações acima mencionadas, compreende-se que o Estatuto da Criança e do Adolescente visa proporcionar um tratamento diferenciado aos jovens que tenham cometido um ato ilícito, devido ao fato de que sua personalidade ainda está em desenvolvimento e este sofre grande influência do ambiente em que vive.

Neste sentido, também há um posicionamento diferenciado para a identificação criminal, se este indivíduo portar quaisquer documentos que comprovem sua identidade, estes terão respaldo para não passarem por outros métodos. É importante identificá-lo corretamente, e só ocorrerá a identificação compulsória sob as exceções permitidas, especialmente quando o menor responsável pela infração utilizou documentos falsos.

Entretanto, é notável que o ECA apresenta certa omissão em relação aos procedimentos para a realização da identificação deste menor em caso de dúvida fundamentada. Há a necessidade de abranger e determinar as ações de identificação criminal para o menor, em que se impõe todas as situações que demandam a identificação e os métodos utilizados para cada caso, respeitando as determinações do ECA.

O presente trabalho cumpriu com o objetivo proposto de demonstrar o modo em que ocorre a identificação criminal de um menor de acordo com a legislação, desta forma, estes serão submetidos ao processo apenas em determinados casos. Contudo, ainda é de suma importância realizar outras pesquisas na área, especialmente para determinar quais os processos de identificação utilizados, e se há o respeito as normas vigentes. 


\section{REFERÊNCIAS BIBLIOGRÁFICAS}

ARAÚJO, Marcos Elias Claudio de PASQUALI, Luis. Datiloscopia: a determinação dos dedos. Brasília- DF. LabPam, 2006.

BOCATO, Vinícius. Quatro razões a favor da não redução da maioridade penal. Pragmatismo Político, Porto Alegre, abr. 2013. Disponível em: https://ww w.pragmatismopolitico.com.br/2013/04/pela-naoreducao-da-maioridade-penal.h tml Acesso em: 15 de agosto de 2020.

BRASIL. Decreto-Lei no 3.689, de 3 de outubro de 1941. Código de Processo Penal.

BRASIL. Lei no $\mathbf{1 0 . 0 5 4}$, de 7 de dezembro de 2000. Dispõe sobre a identificação criminal e dá outras providências.

BRASIL. Lei no 12.037 , de $1^{\circ}$ de outubro de 2009. Dispõe sobre a identificação criminal do civilmente identificado, regulamentando o art. 50, inciso LVIII, da Constituição Federal.

BRASIL. Lei no 8.069, de 13 de julho de 1990. Dispõe sobre o Estatuto da Criança e do Adolescente e dá outras providências.

BRASIL. Lei no 9.034/95, de 3 de maio de 1995. Dispõe sobre a utilização de meios operacionais para a prevenção e repressão de ações praticadas por organizações criminosas

CURY, Munir (Org.). Estatuto da criança e do adolescente comentado, comentários jurídicos e sociais. 11 ed., atualizada de acordo com a Lei 12.010, de 3.8.2009. São Paulo: Malheiros Editores, 2010.

DIGIÁCOMO, Murillo José; DIGIÁCOMO, Ildeara de Amorim. Estatuto da criança e do adolescente anotado e interpretado. Curitiba: Ministério Público de do Estado do Paraná. Centro de Apoio Operacional das Promotorias da Criança e do Adolescente, 2010. 
ELIAS, Roberto João. Comentários ao Estatuto da Criança e do Adolescente: Lei n. 8.069/1990, de 13 de julho de 1990. São Paulo: Saraiva, 1994.

GONSALVES, E. P. Iniciação à pesquisa científica. 3. ed. Campinas: Alínea, 2003. ISHIDA, Válter Kenji. Estatuto da criança e do adolescente: doutrina e jurisprudência. 12 ed. São Paulo: Atlas, 2010.

LOPES, Jr. Direito Processual Penal e sua Conformidade Constitucional. V. 1. Rio de Janeiro: Lumen JurisAury. 2007. MINAYO, M. C. S. O desafio do conhecimento. Pesquisa qualitativa em saúde. São Paulo: HUCITEC, 2007.

MIRABETE, Júlio Fabrini. Código de Processo Penal Interpretado. 5 ed. São Paulo: Atlas. 2000.

NICOLITT, André. Banco de dados de perfis genéticos (DNA): As inconstitucionalidades da Lei 12.654/2012. Boletim IBCCRIM , v. 245, p. 15, 2013.

QUEIJO, Maria Elizabeth. 0 direito de não produzir prova contra si mesmo: o princípio nemo tenetur se detegere e sua decorrências no processo penal. São Paulo: Saraiva, 2012.

QUEIJO, Maria Elizabeth. O princípio nemo tenetur se detegere e a coleta de material genético: identificação criminal ou colaboração na produção da prova? Boletim IBCCRIM, ano 21, n 250, Setembro/2013.

RABELLO, ERALDO. Curso de Criminalista. Porto Alegre: Sagra : DC Luzzatto. 1996. pag. 71 a 101.

ROBLES, Paulo Roberto. Das Impressões digitais nos locais de crime. $1^{\text {a }}$ edição. São Paulo: Editora Paulistajur, 2004.

ROSSATO, Luciano Alves. LÉPORE, Paulo Eduardo. CUNHA, Rogério Sanches. Estatuto da Criança e do Adolescente Comentado. 2 ed. rev., atual. e ampl. São Paulo: Editora Revista dos Tribunais, 2011. 
SAAB, Nadia Maria. A eficácia das medidas socioeducativas. Jus Navigandi, Teresina, jan. 2017. Disponível em: http://www.conteudojuridico.com.br/artigo,aeficacia-das-medidassocioeducativas,57957.html . Acesso em: 15 de agosto de 2020.

SHECAIRA, Sérgio Salomão. Criminologia. 2ed.revista, atualizada e ampliada. São Paulo: Editora Revista dos Tribunais,2008

SOBRINHO, Marcos Sérgio. Identificação Criminal. São Paulo - SP: Revista dos Tribunais, 2003.

TOURINHO FILHO, Fernando da Costa. Processo Penal, $1^{\circ}$ volume, $22^{a}$ edição. São Paulo: Editora Saraiva, 1999.

VELHO, Jesus Antonio; GEISER, Gustavo Caminoto; ESPÍNDULA, Alberi. Ciências Forenses, 3. ed. São Paulo: Millenium, 2017.

VENOSA, Silvio de Salvo. Direito Civil, $1^{\circ}$ volume. 3aㅡ edição, São Paulo, editora Atlas, 2003

VERGARA, S. C. Projetos e relatórios de pesquisa em Administração. 7. ed. São Paulo: Atlas, 2006.

VERONESE, Josiane Rose Petry. Direito da Criança e do Adolescente. Florianópolis: Editora OAB/SC, 2006.

Enviado: Setembro, 2020.

Aprovado: Outubro, 2020. 